Finance and Economics Discussion Series Divisions of Research \& Statistics and Monetary Affairs Federal Reserve Board, Washington, D.C.

\title{
Escaping the Samaritan's Dilemma: Implications of a Dynamic Model of Altruistic Intergenerational Transfers
}

\section{Maria Perozek}

2005-67

NOTE: Staff working papers in the Finance and Economics Discussion Series (FEDS) are preliminary materials circulated to stimulate discussion and critical comment. The analysis and conclusions set forth are those of the authors and do not indicate concurrence by other members of the research staff or the Board of Governors. References in publications to the Finance and Economics Discussion Series (other than acknowledgement) should be cleared with the author(s) to protect the tentative character of these papers. 
Escaping the Samaritan's Dilemma: Implications of a Dynamic Model of Altruistic Intergenerational Transfers

Maria Perozek ${ }^{1}$

15 December 2005

\begin{abstract}
:
This paper explores how altruistic parents structure transfer rules in response to potential incentive problems and how the investment behavior of children is influenced by these transfer policies. To investigate these issues, I develop a dynamic model of altruistic transfers in which transfers can be tied to the purchase of human capital investment. Numerical solutions are examined to provide insight into the predictions of the model for transfer behavior and investment by family size. The dynamic framework developed in the paper is used to guide the interpretation of data on transfers and education investment by children in the Health and Retirement Survey. The data are consistent with the prediction of the model that children in larger families invest more in education conditional on initial transfers.
\end{abstract}

\footnotetext{
${ }^{1}$ The author thanks Morris Davis, Michael Palumbo, John Rust, and Karl Scholz for their helpful comments. This is a revised version of a chapter of my dissertation. The opinions expressed here are those of the author and not necessarily those of the Board of Governors of the Federal Reserve System or its staff. Please address correspondence to Maria Perozek, Federal Reserve Board, mail stop 97, 20th and C Streets NW, Washington DC 20551, USA. Tel: 202 452-2692. Fax: 202 728-5889. Email: mperozek@frb.gov.
} 


\section{Introduction}

Each year, parents provide significant transfers to their adult children. Gale and Scholz (1994) estimate that the aggregate annual flow of inter-vivos transfers from parents to their adult children may total close to $\$ 90$ billion. A complete understanding of transfer behaviorfrom what motivates transfers to the specification of the transfer rules-is essential for predicting the impact of government transfer policies and for understanding intergenerational wealth and income mobility. This paper examines how the incentive effects of altruistic transfer policies influence both the structure of parents' transfer rules and the investment behavior of children.

Few would dispute the proposition that transfer policies provide incentives that may affect the behavior of potential recipients. Like all transfer policies, rules that determine transfers from parents to children may encourage children to take particular actions. For example, if parents are altruistic toward their children, then they will generally provide their children with some informal insurance against the risk of unemployment or low income draws. It is well established that problems of moral hazard may arise when insured individuals can take unobserved actions that influence the probability distribution of the outcome. However, when altruistic parents provide insurance to their children, an incentive problem can arise even when the actions of the child are observable. In particular, an altruistic parent in a dynamic setting faces the Samaritan's Dilemma: If the child understands the altruistic transfer rule, he will behave so that the probability of becoming impoverished is too high (Buchanan, 1975). This inefficiency occurs because the altruistic parent cannot credibly condition future transfers on the behavior of the child.

Previous research explores the efficiency effects of altruism in a dynamic setting (Lindbeck and Weibull, 1988; Bruce and Waldman, 1990; Bruce and Waldman; 1991; Coate, 1995; Bernheim and Stark, 1988). Bruce and Waldman (1990) characterize the equilibria of simple 
dynamic transfer games in which the donor is purely altruistic-that is, the donor cares about the transfer recipient and is not motivated by paternalism or the desire to receive something in return. Their results show that an altruist who cannot commit to future transfers is always worse off than an altruist who has commitment power. However, Bruce and Waldman (1991) show that if an altruistic parent cannot commit but can tie transfers to an observed behavior, such as saving, then the parent can achieve the efficient solution, i.e. the utility level the parent would achieve with commitment power. ${ }^{2}$ These results demonstrate that tied transfers can be efficient for an altruistic parent who does not have paternalistic preferences. ${ }^{3}$

While previous literature has shown that tied transfers are efficient in the context of intergenerational transfers, the implications of a dynamic model of altruistic transfers have not been examined fully. However, one recent paper by Brown, Mazzocco, Scholz and Seshadri (2004) examines tied transfers in a dynamic framework, finding that the proportion of tied transfers increases with parents' wealth and altruism, and that tied transfers and subsequent cash transfers are negatively correlated. While my model is similar in spirit, several differences in specification are non-trivial. For example, in their model, the parent

\footnotetext{
${ }^{2}$ Also, see Coate (1995) for an interesting application to government provision of insurance to the poor. He shows that when the government represents an altruistic population, there is an efficiency rationale for government provision of in-kind transfers of insurance relative to cash transfers.

${ }^{3}$ This finding is contrary to previous results regarding the efficiency of tied transfers. For example, Pollak (1988) argued that tied transfers can only be explained by a paternalistic preference structure for the parents: While the parents care directly about the utility of the child, they must also care directly about the composition of the child's consumption bundle. Although this result is valid in the context of a static framework, it does not obtain in a dynamic model in which children can take actions to manipulate future transfers.
} 
ties transfers by choosing the education level directly, whereas I allow the education choice to be controlled by the child. As noted in section 4.1 below, the implications of the models for the effect of altruism on the proportion of transfers that are tied to education are completely different.

In this paper, I explore how altruistic parents structure transfer policies in response to possible incentive problems, and how optimal investment is influenced by the presence of these altruistic transfer policies. For example, children with more altruistic parents may be more likely to free-ride on parental altruism. Similarly, children in larger families may receive relatively less informal insurance, and thus may be less likely to free-ride. ${ }^{4}$ This paper characterizes altruistic transfer rules in a dynamic setting and explores the effects of these transfer policies on the investment behavior of children.

The paper is structured as follows. Section 2 specifies a dynamic model of family saving and transfer behavior when parents are altruistic and children face uninsurable income risk. In addition to providing direct cash transfers, the parent is allowed to tie transfers to human capital investment by offering to pay some or all of the child's education expenses. Section 3 characterizes the solution of the model and highlights the relative efficiency of tied transfers versus cash transfers. Section 4 reviews the implications of the dynamic model when there is variation in altruism and family size. I show that an important implication of the model is that children from multiple child families will choose at least as much education investment as children from single child families conditional on the amount of educational assistance

\footnotetext{
${ }^{4}$ Lindbeck and Weibull (1988) provide a formal definition of free-riding in the context of dynamic altruism. The intuitive notion is that "An individual is a free-rider if his strategic behavior induces others to contribute more to his welfare than they would like to, had they had the possibility to commit themselves to a support of their own choice" (Lindbeck and Weibull, p.1178).
} 
received. The predictions of the model are then used to guide the interpretation of data on transfers and education investment. In particular, Section 5 shows that data from the Health and Retirement Survey are consistent with the implications of the model for differences in education investment by family size. Section 6 offers concluding remarks and discusses directions for future research.

\section{Intergenerational Altruism with Tied Transfers}

This section develops the implications of a dynamic model of altruistic intergenerational transfers in which children make education investment decisions that influence both their future probability of employment and their income conditional on employment status. I assume that there is one purely altruistic parent and one totally selfish child who are both alive for two periods. Both the parent and the child receive utility from their own consumption according to utility functions characterized by constant relative risk aversion, i.e. $u_{p}(c)=u_{k}(c)=\frac{c^{1-\gamma}}{1-\gamma}$. The altruistic parent also cares about the utility of her child, giving her period utility function the form $u_{p}+\theta u_{k}$, where $\theta$ is the weight placed on the child's utility. While the child can save only through human capital investment, I assume that the parent can borrow and save at a riskless rate of interest. The basic transfer game proceeds as follows. First, the parent chooses saving $A$, first period cash transfers $\tau_{1}$ and first period tied transfers $s$. Second, the child chooses education $e$, and third, the child's second-period employment state and income are revealed and the parent can provide a second period cash transfer $\tau_{2}$.

I assume that the parent has completed her formal schooling and works full time in both periods at an exogenously determined wage rate $\left(W_{p 1}\right.$ and $W_{p 2}$ for the first and second periods respectively). In the first period, the parent allocates resources between saving, 
consumption and transfers to the child. First period transfers can be provided in two forms. First, the parent can transfer cash directly to the child $\left(\tau_{1}\right)$, giving the child complete discretion over how to allocate resources between education investment and current consumption. Alternatively, the parent can tie transfers to education by announcing that she will pay a fixed fraction of the child's education expenses $(s)$. By tying transfers to education, the parent requires the child to invest in education in order to receive the transfer. If a Samaritan's Dilemma exists, the parent is likely to provide a positive education subsidy in order to induce the child to choose a more efficient level of education.

In each period, the child is endowed with one unit of time. In the first period, the child divides his time between investment in education $(e)$ and work at the minimum wage $\left(W_{k 1}\right)$. The benefits to education are two-fold. First, educational attainment influences future labor market earnings, which are assumed to increase with education at a decreasing rate. Second, higher levels of education are associated with lower probabilities of unemployment in the future. For simplicity it is assumed that, conditional on education and employment status, income is exogenous. In addition, the child cannot borrow to finance current education investment or consumption, and the child can save only by investing in education.

After the employment state of the child is realized in period 2, the parent can transfer cash to the child $\left(\tau_{2}\right)$. I also assume that neither the parent nor the child can purchase private insurance against the risk of unemployment.

The model is solved by backward induction. First, in the second period, the parent observes the income level of the child and provides a transfer according to the static altruistic transfer rule, which depends on the resources of the parent and the child in the second period $\left(W_{p 2}+A\right)$ and $\left.W_{k 2}(e \mid e m p)\right)$, respectively, as well as the level of parental altruism $(\theta)$. In particular, the second period transfer will be operative if $\theta^{-1 / \gamma}\left(W_{p 1}+A\right)>W_{k 2}(e \mid e m p)$, and inoperative otherwise. If the second period transfer is operative, then the parent and the 
child each consume a fraction of the total family resources $\left(W_{p 2}+A+W_{k 2}(e \mid e m p)\right)$ :

$$
\begin{aligned}
& C_{k 2}=\frac{1}{1+\theta^{-1 / \gamma}}\left(W_{p 2}+A+W_{k 2}(e \mid e m p)\right) \\
& C_{p 2}=\frac{\theta^{-1 / \gamma}}{1+\theta^{-1 / \gamma}}\left(W_{p 2}+A+W_{k 2}(e \mid e m p)\right)
\end{aligned}
$$

where $A$ is the saving of the parent, $\theta$ is the weight that the parent places on the child's lifetime utility, and emp $\in\{0,1\}$ denotes the employment status of the child, where 0 represents unemployment and 1 represents employment. ${ }^{5}$ Otherwise, if the second period transfer is not operative, then the parent and the child each consume their own second-period resources:

$$
\begin{gathered}
C_{k 2}=W_{k 2}(e \mid e m p) \\
C_{p 2}=W_{p 2}+A
\end{gathered}
$$

In the second stage of the backward induction, the child observes the saving of the parent $A$, the fraction of education costs paid by the parent $s$, and the amount of the first period cash transfer $\tau_{1}$, and chooses education investment e to maximize expected lifetime utility:

$$
\max _{e} \frac{c_{k 1}^{1-\gamma}}{1-\gamma}+\beta E \frac{c_{k 2}^{1-\gamma}}{1-\gamma}
$$

subject to

\footnotetext{
${ }^{5}$ For simplicity, I assume that the rate of return on saving is zero.
} 


$$
\begin{aligned}
0 \leq e & \leq 1 \\
C_{k 1} & =W_{k 1}(1-e)-(1-s) p_{e} e+\tau_{1} \\
C_{k 2} & = \begin{cases}\frac{1}{1+\theta^{-1 / \gamma}}\left(W_{p 2}+A+W_{k 2}(e \mid e m p)\right) & \text { if } \tau_{2}>0 \\
W_{k 2}(e \mid e m p) & \text { otherwise }\end{cases} \\
W_{k 2}(e \mid e m p) & = \begin{cases}W_{k 2}(e) & \text { w.p. } 1-p_{u}(e) \\
b W_{k 2}(e) & \text { w.p. } p_{u}(e)\end{cases}
\end{aligned}
$$

where $\beta$ is the discount factor, $p_{e}$ is the price of education, and $W_{k 1}$ is first period income, which is reduced by current investment in education. The probability of unemployment, $p_{u}(e)$, is assumed to decrease with education at an increasing rate. The child's second period income, $W_{k 2}(e \mid e m p)$, depends both on unemployment status and education level. If the child is employed in the second period, then he works full time at a wage that is increasing in education at a decreasing rate, (i.e. $\left.W_{k 2}^{\prime}(e)>0, W_{k 2}^{\prime \prime}(e)<0\right)$. Alternatively, if the child is unemployed, then he receives an unemployment benefit, $b W_{k 2}(e)$, where $b<1$ is a constant wage replacement rate. The child's decision rule for investing in education, $e^{*}\left(s, \tau_{1}, A\right)$, will therefore be a function of the parent's saving choice and transfers to the child, as well as other factors such as the return to education that is determined by $W_{k 1}, W_{k 2}, p_{u}(e)$, and $p_{e}$.

In the final stage, the parent chooses $s, \tau_{1}$, and $A$ to maximize expected lifetime utility:

$$
\max _{s, \tau_{1}, A} \frac{c_{p 1}^{1-\gamma}}{1-\gamma}+\beta E \frac{c_{p 2}^{1-\gamma}}{1-\gamma}+\theta\left(\frac{c_{k 1}^{1-\gamma}}{1-\gamma}+\beta E \frac{c_{k 2}^{1-\gamma}}{1-\gamma}\right)
$$

subject to 


$$
\begin{aligned}
\mathrm{C}_{k 1} & =W_{k 1}(1-e)-(1-s) p_{e} e+\tau_{1} \\
C_{p 1} & =W_{p 1}-\tau_{1}-s p_{e} e-A \\
C_{k 2} & = \begin{cases}\frac{1}{1+\theta^{-1 / \gamma}}\left(W_{p 2}+A+W_{k 2}(e \mid e m p)\right) & \text { if } \tau_{2}>0 \\
W_{k 2}(e \mid e m p) & \text { otherwise }\end{cases} \\
C_{p 2} & = \begin{cases}\frac{\theta^{-1 / \gamma}}{1+\theta^{-1 / \gamma}}\left(W_{p 2}+A+W_{k 2}(e \mid e m p)\right) & \text { if } \tau_{2}>0 \\
W_{p 2}+A & \text { otherwise }\end{cases} \\
e & =e^{*}\left(s, \tau_{1}, A\right)
\end{aligned}
$$

where $e^{*}\left(s, \tau_{1}, A\right)$ is the child's education investment rule. If the parent's second period transfer is operative with positive probability, then the parent will likely choose a positive education subsidy $s$ in order to reduce the inefficiency caused by her inability to commit.

The solution described in this section assumes that the parent cannot commit to second period transfers. However, it is useful to review the solution to the social planning problem when the parent's lifetime utility is weighted by 1 and the child's lifetime utility is weighted by $\theta$. This solution, which amounts to giving the parent the ability to commit to second period transfers and to control child's education, represents the first-best solution from the perspective of the parent. This solution, which we will refer to below as the "commitment case", or the "first best solution", is distinct from the case where the parent can commit to second period transfers but cannot choose education directly; because the child still controls education investment, the parent's utility in that case is generally less than the first-best solution, but greater than in the no-commitment case. ${ }^{6}$

${ }^{6}$ In general, in the first-best solution, the parents choose education and second period transfers that 
In the absence of tied transfers, the altruistic parent will not be able to achieve the first-best utility in a dynamic setting. However it is important to note that even when tied transfers are available, as in the model described above, the parent will not generally be able to achieve the first-best solution. While Bruce and Waldman (1991) show that tied transfers enable the parent to achieve the efficient solution, this result relies upon the ability of the parent to dictate the level of investment for the child, e.g. if the parent wants to ensure that her child receives a college diploma, she need only pay the school directly for the cost of the education and the child will receive the diploma. In contrast, the model proposed in this paper gives the child complete discretion over the choice of education level. This specification was chosen to reflect the important real-world consideration that it is children, not parents, who ultimately choose to acquire human capital, both in terms of attending school and in the unobservable effort applied. Because the parent does not choose education directly, the parent may not be able to achieve the efficient solution-even when the maximum subsidy to education is offered.

\section{Solving the Model}

At this level of generality, there is no closed form solution to this model and it is not possible to derive analytically the comparative statics of interest. Hence, the net effect of changes in the parameters and exogenous variables of the model can only be determined by solving the

result in a time-consistent transfer to the child in period 2 -that is, the transfer is optimal ex post conditional on education and employment status. In contrast, if the parent can commit to second period transfers but cannot control education, then the parent typically commits to a lower second period transfer than is optimal ex post given the child's education choice. 
model numerically for a specific parameterization. The numerical solutions are computed by conducting a grid search over the control variables of the parent: first period cash transfers, $\tau_{1}$, first period education subsidy $s$, and saving $A$. In the no-commitment case, the parent takes the child's optimal education decision $e^{*}\left(s, \tau_{1}, A\right)$ as given, and chooses $\left(s, \tau_{1}, A\right)$ to maximize expected lifetime utility. In contrast, in what we will call the commitment case, the parent chooses all transfers, saving and education investment directly $\left(s, \tau_{1}, \tau_{2}, A, e\right)$ to maximize expected lifetime utility.

\subsection{Specification of the Model}

The stylized 2-period model described above is designed to provide insights into the qualitative features of altruistic transfer rules in a dynamic setting. To uncover these qualitative results, I examine how the solution to the model evolves with changes in model parameters and other features, such as the number of children in the family. Tocompute numerical solutions to the model, it is necessary to specify parameter values and distributional assumptions underlying the income process and the unemployment probability. Of necessity, there is a certain amount of arbitrariness to these specifications; that said, where possible, functional forms are chosen to reflect certain features of the data. For example, it is well-documented that education raises expected wages and reduces future unemployment (e.g. Card, 2000; Padula and Pistaferri, 2001). As a result, our specification implies that education investment increases the expected value of future wages at a decreasing rate, and also lowers the variance of income by reducing the probability of unemployment. In particular, the probability of unemployment is assumed to decrease with education at an increasing rate according to the process $\exp (-\phi e)$, where $\phi>0$.

If the child is employed in the second period, then he must work full time at a wage that 
is determined by education according to the following process $W_{k 2}(e)=W_{k 1}(1+\rho e)^{\alpha}$, where the parameters $\alpha$ and $\rho$ determine the return to education. It is assumed that $0 \leq \alpha \leq 1$ and $\rho>0$, so that the wage $W_{k 2}(e)$ increases with education at a decreasing rate. In contrast, if the child is unemployed in period 2, then he receives an unemployment benefit $b W_{k 2}(e)$, where $b \in[0,1]$ is a constant wage replacement rate.

The model is initially calibrated using the following parameterization:

$$
\begin{aligned}
\mathrm{W}_{p 1} & =W_{p 1}=7.5 \\
W_{k 1} & =5 \\
\theta & =.5 \\
\alpha & =.7 \\
\rho & =1.75 \\
\gamma & =2.0 \\
p_{e} & =1.0 \\
\phi & =3.0 \\
b & =.5
\end{aligned}
$$

To demonstrate the efficient solution and to illustrate the optimality of tied transfers, the following section presents the solution to the model under different assumptions regarding the parent's ability to commit and access to tied transfers.

\subsection{The Solution}

\subsubsection{No Tied Transfers}

To illustrate the inefficiency that arises due to the inability to commit, it is useful to examine the commitment case to establish a benchmark for the optimal solution. As noted above, the commitment case yields the maximum utility attainable for the parent, and results in 
the efficient level of education investment by the child. In contrast, if the parent cannot commit and is not allowed to tie transfers to education, then the results from Bruce and Waldman (1990) imply that the parent cannot attain the commitment level utility. However, if the parent is allowed to tie transfers to education, the results from Bruce and Waldman (1991) suggest that the parent may be able to attain the efficient solution, and therefore the commitment level utility.

Table 1 presents the results from the baseline model specification under different assumptions about the commitment power of the parent and the ability to tie transfers to education. In the commitment case, shown in column 1, the parent chooses education and the allocation of resources in each period; therefore, the composition of the first period transfer is irrelevant. In this case, which represents the efficient solution, the parent gives a first-period transfer of 1.49 and chooses an education level of .31 for the child. If the child is unemployed in the second period, then the parent transfers .9, which is equal to the altruistic transfer conditional on the child's income when unemployed.

In contrast, column 2 shows that when parents do not have commitment power and can only provide cash transfers, the investment levels of both the child and the parent are lower than the efficient levels shown in column 1, with the child choosing an education level of .265-about 15 percent lower than the commitment case-and the parent choosing to borrow .81-50 percent more than in the commitment case. These results illustrate that the parent will undersave in the first period in order to fund larger first period transfers to encourage the child to invest in education. The child, whose second-period income is effectively taxed, chooses to spend a greater fraction of the larger first period transfer on current consumption. In general, when parents are altruistic toward children, both parents and children will undersave relative to the efficient (commitment) solution. That is, $e^{* N C} \leq$ 
$e^{* C}$ and $A^{* N C} \leq A^{* C}$, where $N C$ denotes no commitment and $C$ denotes commitment case. ${ }^{7}$

\subsubsection{Tied Transfers}

As noted above, the availability of tied transfers can improve the welfare of the altruistic parent because given the same level of expenditure in the first period, i.e. cash transfers plus amount of education subsidy, the child will choose more education when the parent pays for education relative to when the parent gives the full first period transfer in the form of cash. Figure 1 shows the child's education decision when the parent provides a full education subsidy versus when the parent provides no education subsidy, holding constant the total amount of the first period transfer and parental saving. The results indicate that parents get "more bang for the buck" when they tie transfers to education-that is, for the same dollar amount of first period transfer, the child always chooses a higher level of education when the parent provides a full education subsidy.

The third column in table 1 shows that the boost to education investment provided by tied transfers allows the altruistic parent without commitment power to come closer to the efficient solution. When tied transfers are available, the parent chooses to provide a full education subsidy $\left(s^{*}=1\right)$ in addition to a cash transfer of 1.33 , and the child chooses an education level of .29, as opposed to .31 in the commitment case. Although the education choice is still lower than the efficient case, the parent is much better off in this scenario than

\footnotetext{
${ }^{7}$ The main result that the parent and the child overconsume family resources in the first period appears to be quite robust to changes in the specification of the returns to education and other parameters (not reported). However, in some cases, the education choice of the child can actually be higher in the nocommitment case if the parent's undersaving coupled with higher returns to education implies zero probability of a transfer in the second period. Even in this case, however, the family overconsumes in the first period.
} 
in the case where only cash transfers were available. The utility improvement for the parent, noted in row 9, stems from the parent's ability to use tied transfers to induce a greater level of education investment with a smaller first period total transfer, which is shown in row 4 . When tied transfers are available, total first period transfers were substantially lower (1.62 vs. 1.77) and parental saving substantially higher (-.69 vs. -.81). Because the optimal education investment is also higher (.29 vs. .265), second period wages are higher and the probability of unemployment is lower, which implies that the child will be less likely to need a transfer in the second period.

In sum, the total value of the first period transfer is lower when tied transfers are available, and, the education level chosen by the child is higher. ${ }^{8}$ Because the parent does not need to borrow as much in the first period to fund these transfers, she saves more when tied transfers are available. Although the parent is still unable to achieve the commitment level utility in this case, she can get much closer to the efficient solution when tied transfers are available. Taken together, the results from table 1 illustrate the importance of including tied transfers in a dynamic model of transfer behavior. In particular, the saving and transfer patterns of the parent are very different when tied transfers are included: Parents who cannot commit will save more and transfer less over their lifetimes when tied transfers are available.

\footnotetext{
${ }^{8}$ Robustness checks indicate that child's education is higher when tied transfers are available if the cashonly solution implies positive probability of a second-period transfer. However, in all specifications, first period transfers were lower when tied transfers are available.
} 


\section{Implications of the Model}

\subsection{Variation in Altruism}

This section explores how changes in the degree of altruism influence the equilibrium transfers of the parent and education investment of the child. Parents with relatively low altruism parameters do not care as much about the welfare of their children as parents with higher altruism parameters. As a result, less altruistic parents will desire to allocate less of the family's resources to the child, resulting in lower transfers conditional on income in both the first and the second periods. Table 2 shows that the effect of changes in altruism on total transfers are consistent with these expectations: As the altruism parameter rises from .25 to .75 , the total value of the first period transfer rises, as does the second period transfer conditional on employment status.

A less obvious result is that the distribution of first period transfers between tied transfers and cash may vary systematically with the level of parental altruism. Because the less altruistic parent can credibly commit to lower second period transfers, one might think that the less altruistic parent does not need to tie as large a fraction of the transfer to education as the more altruistic parent. Figure 2 shows that children of more altruistic parents choose lower levels of education conditional on receiving a full education subsidy $(s=1)$ and no cash additional cash transfer in the first period, holding second period resources constant. These effects can be significant: The child's education choice falls from .2 when $\theta=.25$ to 0 when $\theta \geq .70$.

However, as long as the transfer is operative with positive probability in the second period, it is likely that some level of tied transfers will be efficient for the parent. Also, because the child can attain a higher level of utility when transfers are given as cash, more

altruistic parents may actually tie a lower proportion of total transfers to education. Hence, 
the net effect of a change in the level of altruism on the composition of first period transfers is ambiguous.

The results from table 2 illustrate the effect of altruism on the composition of transfers between tied transfers and cash: In this model, higher levels of altruism are associated with lower ratios of tied transfers to total transfers. This is in part an artifact of the model specification, in which the amount of resources that can transferred to the child via an education subsidy is constrained to be less than or equal to 1, which is the price of education multiplied by the highest education choice. Therefore, more altruistic parents want to allocate a larger proportion of family resources to the child, and once they max out on education, they must transfer cash. Because the education subsidy is going to be the most efficient way for all altruistic parents to transfer resources, the proportion of total transfers tied to education will fall as altruism levels increase; that is, parents will start by giving the maximum subsidy $(s=1)$ then begin to dole out cash.

\subsection{Multiple Child Families vs. Single Child Families}

The previous section showed that children of less altruistic parents receive less informal insurance against future income shocks than children of more altruistic parents. As a result, they choose higher levels of education for any given first period transfer. A similar reduction in informal insurance takes place when children have siblings. In particular, if there are more children competing for transfers, then the additional risk of having to 'share' the transfer in the second period may reduce the incentive to free-ride on the parent's altruism. In effect, children in multiple child families will have less informal insurance against future income shocks than children in single child families. This section investigates the differences in the level and composition of transfers per child between families with two children and otherwise 
similar families with just one child.

The model becomes more complicated when an additional child joins the family because each child's education choice in period one influences the other child's expected transfer in period two. For example, if both children are unemployed in period two, then they each receive a smaller transfer than if they were the only unemployed child. Hence, in period two, the child receives a transfer that depends not only on his own employment status, but also on his sibling's employment status. As a result, the child must take into account his sibling's education choice when choosing his own education investment. I assume that children choose their education levels simultaneously given the first period transfers and saving of the parent $\left(s, \tau_{1}, A\right)$. Hence, the education choice of each child must maximize the child's expected lifetime utility conditional on the other child's education choice. ${ }^{9}$

For simplicity, I assume that the two children are identical, and that the parent cares for each child equally. To facilitate comparison between one and two child families, an assumption must be made regarding the extent to which parents with two children care for each child relative to parents with one child. Recall that a parent with one child weights that child's utility by the altruism parameter $\theta$. If a parent with two children weights each child's utility by $\theta$, then that parent has effectively become more altruistic than the parent of an only child in that she consumes less; that is, the children's utility has a greater weight relative to the parent's utility from her own consumption relative to the one-child case. However, for the purpose of comparing across families of different sizes, this specification is useful because it ensures that each child faces a similar set of incentives from the parent, with the exception that children with siblings face an added risk of receiving a lower transfer when their sibling

\footnotetext{
${ }^{9}$ There would presumably be effects by birthorder if older children make education decisions before younger children, and the younger child can observe this choice. We leave this extension for future work.
} 
is unemployed. Hence, the parent in each family chooses transfers to set her own marginal utility of consumption equal to the marginal utility of consumption for each child weighted by $\theta$, i.e. $M U_{p} \geq \theta M U_{k} \cdot{ }^{10}$.

Table 3 shows how equilibrium transfers per child change when the number of children in the family increases from one to two. For the numerical solutions presented in table 3, I assume that the families are identical in all respects except for family size, with initial conditions and parameters set equal to the baseline specification described in Section 3.1. Column 1 shows the base case results for the one child family, and column 2 presents transfers per child for the two child family under the assumption that each child's utility is weighted by $\theta$.

In both cases, the parent provides a full subsidy to the purchase of education. However, relative to an only child, the child who has a sibling receives a smaller cash transfer in the first period (.77 vs. 1.33), implying that a larger proportion of the first period transfer is tied to education. Given these first period transfers and the parent's choice of saving-which in both cases is roughly the same at -.69 for the one kid family and -.68 for the two kid familythe child chooses education. Figure 3 illustrates the education decisions as a function of the

\footnotetext{
${ }^{10}$ Alternatively, one might argue that it is more realistic to assume that families with multiple children weight each child's utility by $\frac{\theta}{N}$, where $N$ is the number of children in the family. This assumption implies that parents with more than one child do not care as much for each child as parents with only one child. As a result, the parent would generally equate her marginal utility of consumption to the marginal utility of each child weighted by $\frac{\theta}{N}$, i.e. $M U_{p} \geq \frac{\theta}{N} M U_{k}$. Because $\frac{\theta}{N}<\theta$, it is clear that transfers in this case will be lower than transfers in families where each child's utility is weighted by $\frac{\theta}{N}$. In fact, it is possible that transfers to children are no longer operative in this case, and hence the Samaritan's Dilemma would not be an issue
} 
first period cash transfer for children in one-child families and children in 2-child families when the parent provides a full education subsidy and borrows .68, which fixes second period resources. Notice that for every cash transfer offered, children in two-child families choose higher levels of education than children in one-child families. This difference is especially large for first dollars of cash transfers; given no cash transfer, children in two-child families will choose education of .185, whereas kids in one-child families will choose education of .125-one third lower than in the two-child case. The optimal education choices for children in these families are highlighted on the graph: In the two-child family, the child chooses education of .26, which corresponds to a cash transfer of .77, and in the one-child family, the child chooses education of .285 , which corresponds to a cash transfer of $1.33 .^{11}$

The difference in education choice among children in different-sized families given the same first period transfer results from lower expected second period transfers in the event that both children are unemployed at the same time. As shown in the lower half of table 2 , the child with a sibling is unemployed, and therefore receives a transfer, with probability .46. However, as noted above, the child's transfer conditional on unemployment depends on the employment status of his sibling. Conditional on unemployment, the child's sibling will be employed with probability .54 , and the child will receive the same level of altruistic transfer had he been an only child in the same financial condition, in this case, .92. But with probability .46, the child's sibling will also be unemployed, and the child will receive a lower transfer of .65. As a result, the child that has a sibling faces not only a lower expected transfer, but also a riskier second period income than the only child. These factors underlie the choice to invest in greater levels of education conditional on first period transfers in fam-

\footnotetext{
${ }^{11}$ This differs a touch from the equilibrium in the one-child case shown in table 2 , as parent's saving is a touch lower in that case (-.69 vs. -.68).
} 
ilies with multiple children. Therefore, it seems reasonable to make the following prediction:

Children in multiple child families will always have less incentive to free-ride on the parent's altruism, ceteris paribus. Hence, given the same level of first-period transfers, they will choose an education level at least as high as children from single child families: $\left(e_{k=2}^{*} \mid s, \tau_{1}\right) \geq$ $\left(e_{k=1}^{*} \mid s, \tau_{1}\right)$.

The empirical analysis presented below explores whether the data are consistent with this prediction of the dynamic model.

\section{Empirical Results}

The theory developed above characterizes the equilibrium transfers from parents and education investment of children under different assumptions regarding family size. This section explores whether empirical evidence from the Health and Retirement Survey is consistent with the predictions of the dynamic model for the effect of family size on transfer behavior and educational investment. I find that the education investment decisions of children are consistent with a dynamic model of altruistic transfers.

\subsection{The Health and Retirement Survey}

The data used in this analysis are from the first wave of the Health and Retirement Survey (HRS). Initial interviews were conducted in 1992 and provide detailed information on the health status and economic status of a nationally representative sample of 12,654 persons aged 51 to 61 and their spouses. In addition, the survey collected information on personal 
characteristics of adult children related to the respondent or the spouse.

Variables of particular importance include measures of transfers over $\$ 500$ to adult children during the year prior to the initial interview. If the child received a transfer, then the survey asks whether any part of the transfer was given for the purpose of financing education or purchasing a home. The survey also asks the respondents to estimate the total amount they have spent for the education of their children. This variable provides important information on past education subsidies that is useful for investigating whether the data are consistent with the implications of the model for differences in education investment and transfer behavior by family size.

\subsection{Transfers and Family Size}

This section explores whether the HRS data on education investment and transfers are consistent with the prediction that children in multiple child families will choose at least as much education as children in single child families given the same level of transfers. Table 4 presents means of child and parent characteristics from a sample of children from families with 1 to 3 children, all of whom are at least 25 years old and live apart from the respondent. Row 1 shows that the average education level is higher for children in two-child families than for children in single-child families (13.41 vs. 13.27), although the difference is not statistically significant at high levels of confidence. However, this result is still striking because the average amount of education assistance provided per child in the two-child families is significantly lower than that provided to children from single-child families $(\$ 8,468$ vs. 3,251$) .{ }^{12}$

\footnotetext{
${ }^{12}$ Education assistance per child is calculated by dividing the total amount of money spent on education by the number of children in the family. The results below are similar when the total amount of education
} 
These results are consistent with the dynamic model of altruism in which children from multiple child families have a greater incentive to invest in education given any 'first period' transfer. Moreover, this result would be somewhat surprising in the context of static models of transfer behavior, which would predict equal investment given equal transfers for observationally identical children from different sized families.

The dynamic model presented in this paper predicts that the average "second-period" transfer conditional on receipt will be smaller than the average transfer to children in onechild families. Table 4 indicates that the HRS data are consistent with these predictions for families with 1 to 3 children. In particular, the average transfer conditional on receipt for children in two-child families was about $\$ 2,200$, significantly lower than the $\$ 3,200$ received by children in one-child families. Although the dynamic model developed above does not make predictions about the probability of receiving a transfer, the table shows that the probability of receiving a transfer in the year prior to the interview falls as family size increases: One-quarter of children from single child families received a transfer as opposed to .19 and .14 of children from two-child and three-child families respectively. ${ }^{13}$

The descriptive results presented in Table 4 appear to be consistent with the dynamic model of altruistic transfers presented in this paper. A particularly striking result is that children in two-child families are more educated even though they receive lower per child transfers for education. ${ }^{14}$ However, the simple descriptive statistics presented above do not assistance is divided by the total number of years of education attained by the children.

${ }^{13}$ It is interesting to note that the probability that a parent gives at least one transfer increases with family size. This may be expected because the larger number of children increases the reisk that at least one of them will be unemployed or receive a low income draw.

${ }^{14}$ Note that the HRS data are not ideal for estimating education investment functions. However, because 
control for characteristics of the parent that might influence the education choice of the child. To examine whether differences in education investment persist after controlling for parent and child characteristics, I estimate an ordered probit using the same sample as Table 4. The dependent variable is the educational attainment of the child, which is divided into five distinct groups by highest grade completed: (1) less than high school; (2) high school graduate; (3) some college; (4) college graduate; (5) some graduate school and above. The econometric specification includes child and family characteristics that may be expected to influence education choice, such as education level, current income, and net worth of the parent, as well as family size and amount of educational assistance provided by the parent. In addition, interaction terms are included to determine the separate effects of educational assistance by family size.

Table 5 presents the coefficient estimates from the ordered probit. ${ }^{15}$ It is not surprising that increases in parental assistance for education are associated with increases in educationafter all, one must go to school to receive this type of financial insurance. However, the negative coefficient estimates on the family size-education assistance interaction terms indicate that the effect of the education subsidy is smaller for children in one child families than for children in families with either two or three children. That is, given the same education subsidy, children in larger families choose higher levels of education. This result is consistent with the prediction that children who have less informal insurance will choose higher levels of education, ceteris paribus. ${ }^{16}$

the data provide unique information on financial transfers for education, it is possible to gain some insight into the education investment decisions of children in the sample.

${ }^{15}$ OLS estimates are similar.

${ }^{16}$ This interpretation of the regression results depends on the assumption that the price and quality of 
These results illustrate that the differences in education choice by family size persist even after controlling for relevant individual and family characteristics. Because education levels and education subsidies are jointly determined in the dynamic model presented in this paper, the ordered probit estimates are intended for descriptive purposes only. In addition, one might argue that factors outside the model may also influence the interpretation of these results. For example, if fertility is endogenous, then the estimated effect of family size on educational attainment will be inconsistent. For descriptive purposes, however, it is interesting to calculate the distribution of educational attainment by children in different families for different total education transfers. For example, holding all other variables at the average level for single child families, a decrease in the education transfer to the average amount given to a child from a two child family results in an 11 percent decrease in the proportion of only children who have at least a college degree (.223 to .199). In contrast, if all other characteristics are held at the mean for two-child families, an increase in the education transfer to the average received by a single child results in a 15 percent increase in the proportion of children who have at least a college degree (.26 to .30). Hence, the difference in educational attainment by family size and education assistance appears to be economically significant.

The results presented in this section show that relative to children with one sibling, only children obtain less formal schooling, receive more financial help from their parents toward their education, are more likely to receive a transfer and receive larger transfers conditional education purchased is constant across all families. For example, if children in small families are more likely to attend more expensive private schools that provide higher quality education, then the conclusion that children in larger families choose higher levels of education conditional on the education subsidy may be incorrect. 
on receipt after age 25. These results are consistent with the implication of the dynamic model of altruistic intergenerational transfers that only children are more likely to free-ride on parental altruism by failing to take actions that decrease the probability that a transfer is needed in the future.

\section{Concluding Remarks}

As Rosenzweig and Wolpin (1993) note, the investment behavior of children is likely to depend not only on their own income and assets, but also on the rules that determine transfers within families. This paper examines how the transfer rules of altruistic parents influence the investment decisions of children. Numerical methods are used to derive predictions about how incentive effects of dynamic altruistic transfer policies may vary with observable characteristics of the family. These predictions are then used to guide the interpretation of recent data on transfers and human capital investment decisions of the child.

A striking implication of the model is that children in multiple child families will choose at least as much education as children in single child families conditional on the education subsidy in the first period. Indeed, the HRS data are consistent with this implication: Children from two-child families invest more in education than children in one-child families, even though they receive less money for education. These results suggest that the amount of informal insurance provided varies across families of different sizes, and that the investment behavior of children varies with family size in ways that theory would predict.

It is likely that many important behavioral effects of altruistic transfer policies are more subtle than the education decision discussed in this paper. In particular, a child with more insurance may be more likely to undertake risky investments. For example, children may be more willing to start their own business, or to choose college majors with less certain financial 
rewards., Indeed, Saks and Shore (2004) find that children from wealthier families tend to choose college majors that are associated with riskier income streams, such as business. In addition, children with greater levels of informal insurance may put forth less effort on the job or at school, and they may maintain lower levels of savings. It would be interesting to explore further whether these behaviors do in fact differ across children from families that provide different levels of informal insurance.

It is also interesting to note that tied transfers comprise a major proportion of transfers-at least 20 percent-for adult children of all ages. This result suggests that the simplified twoperiod version of the dynamic transfer game specified in Section 2 may be inappropriate. Instead, the transfer game might be more appropriately modeled as a repeated game in which transfers can be tied to a given investment commodity in each period. One might conjecture that this specification of the model would reduce the Samaritan's Dilemma type inefficiency since the parent can continually tie transfers to ensure that the efficient action is taken. However, one might also conjecture that as long as the discount factor is strictly less than one, the inefficiency of dynamic altruism will persist even in games with repeated interactions. In any case, it is possible that the transfer rules of the parent may be more complex than those derived from the simple model presented in this paper.

While this paper takes an important first step toward understanding the dynamics of transfer behavior, further research is necessary to develop the implications of the dynamic framework under alternative assumptions regarding reciprocity and exchange behavior. In future work, I will also explore the implications of the repeated transfer game in order to gain additional insight into the dynamics of transfer behavior. 


\begin{tabular}{|c|c|c|c|}
\hline & \begin{tabular}{l|l|}
\multicolumn{2}{|c|}{ Table 1: Optimal Transfers with and with } \\
\end{tabular} & \multicolumn{2}{|c|}{ No Commitment Power } \\
\hline & & $\begin{array}{l}\text { Cash Transfers } \\
\text { Only }\end{array}$ & $\begin{array}{c}\text { Both Cash } \\
\text { and Tied } \\
\text { Transfers }\end{array}$ \\
\hline 1. Education investment $\left(\mathrm{e}^{*}\right)$ & .31 & .265 & .29 \\
\hline \multicolumn{4}{|l|}{ First-period transfers } \\
\hline 2. Education subsidy $\left(\mathrm{s}^{*}\right)$ & --- & --- & 1.0 \\
\hline 3. $\quad$ Cash transfer $\left(\tau_{1}^{*}\right)$ & 1.49 & 1.77 & 1.33 \\
\hline 4. Total value of transfer $\left(\tau_{1}+\mathrm{pe}_{\mathrm{e}}^{*} \mathrm{~S}^{*} \mathrm{e}^{*}\right)$ & 1.49 & 1.77 & 1.62 \\
\hline \multicolumn{4}{|l|}{ Second-period transfers } \\
\hline 5. Cash $\left(\tau_{2}^{*}\right) \mid$ employed & 0 & 0 & 0 \\
\hline 6. $\quad$ Cash $\left(\tau_{2}^{*}\right) \mid$ unemployed & .90 & .86 & .87 \\
\hline 7. Probability of unemployment & .39 & .45 & .42 \\
\hline 8. Parent's saving (borrowing) & -.54 & -.81 & -.69 \\
\hline 9. Parent's lifetime utility & -.5035 & -.5056 & -.5040 \\
\hline 10. Kid's lifetime utility & -.3974 & -.3866 & -.3918 \\
\hline
\end{tabular}

${ }^{1}$ In this case, the composition of first period transfers is irrelevant; the solutions with and without cash transfers are identical. 


\begin{tabular}{|l|c|c|c|}
\hline \multicolumn{4}{|c|}{ Table 2: Optimal Education and Transfers by Altruism Level } \\
\hline & $\theta=.25$ & $\begin{array}{c}\text { Base case: } \\
\theta=.5\end{array}$ & $\theta=.75$ \\
\hline 1. Education investment $\left(\mathrm{e}^{*}\right)$ & .20 & .29 & .36 \\
\hline First-period transfers & & & \\
\hline 2. Education subsidy $\left({ }^{*}\right)$ & & & \\
\hline 3. Cash transfer $\left(\tau_{1}{ }^{*}\right)$ & 1.0 & 1.0 & 1.0 \\
\hline & 0 & 1.33 & 2.24 \\
\hline 4. Total value of transfer $\left(\tau_{1}+\mathrm{pe}^{*} \mathrm{~s}^{*} \mathrm{e}^{*}\right)$ & .2 & 1.62 & 2.6 \\
\hline 5. Percent of transfer tied to education & $100 \%$ & $18 \%$ & $14 \%$ \\
\hline & & & \\
\hline Second-period transfers & & & \\
\hline 6. Cash $\left(\tau_{2}{ }^{*} \mid\right.$ employed & 0 & 0 & 0 \\
\hline 7. Cash $\left(\tau_{2}{ }^{*}\right) \mid$ unemployed & .43 & .87 & 1.07 \\
\hline 8. Probability of unemployment & & & \\
\hline & .55 & .42 & .34 \\
\hline 9. Parent's saving (borrowing) & & & \\
\hline & -.04 & -.69 & -1.13 \\
\hline 10. Parent's lifetime utility & & & \\
\hline 11. Kid's lifetime utility & -.3946 & -.5040 & -.5973 \\
\hline
\end{tabular}




\begin{tabular}{|c|c|c|c|}
\hline \multicolumn{4}{|c|}{ Table 3: Optimal Education and Transfers per Child by Family Size } \\
\hline & One Kid & Two Kids & $\begin{array}{c}\text { Memo: } \\
\text { Efficient } \\
\text { Solution } \\
\text { Two Kids }\end{array}$ \\
\hline 1. Education investment $\left(\mathrm{e}^{*}\right)$ & .29 & .26 & 275 \\
\hline \multicolumn{4}{|l|}{ First-period transfers } \\
\hline 2. Education subsidy $\left(\mathrm{s}^{*}\right)$ & 1.0 & 1.0 & --- \\
\hline 3. Cash transfer $\left(\tau_{1}^{*}\right)$ & 1.33 & .77 & .98 \\
\hline 4. Total value of transfer $\left(\tau^{*}{ }_{1}+\mathrm{pe}^{*} \mathrm{~s}^{*} \mathrm{e}^{*}\right)$ & 1.49 & 1.03 & .98 \\
\hline \multicolumn{4}{|l|}{ Second-period transfers } \\
\hline 5. Cash $\left(\tau_{2}^{*}\right) \mid$ both kids employed & 0 & 0 & 0 \\
\hline $\begin{array}{l}\text { 6. Cash }\left(\tau_{2}^{*}\right) \mid \text { kid unemployed, sibling } \\
\text { employed (to unemployed kid only) }\end{array}$ & .87 & .92 & .93 \\
\hline 7. Cash $\left(\tau_{2}{ }^{*}\right) \mid$ both kids unemployed & --- & .65 & .66 \\
\hline 8. Probability of unemployment & .42 & .46 & .44 \\
\hline 9. Parent's saving (borrowing) & -.69 & -.68 & -.60 \\
\hline 10. Parent's lifetime utility & -.5040 & -.7491 & -.7487 \\
\hline 11. Kid's lifetime utility & -.3918 & -.4204 & -.4232 \\
\hline
\end{tabular}

*Baseline specification $\gamma=2, \theta=.5$. 
Table 4: Means of Child and Family Characteristics by Family Size

Sample: Families with 1 to 3 Children in which All Children Over 25 and Living Away

\begin{tabular}{|c|c|c|c|c|}
\hline \multirow{2}{*}{ Variable } & \multicolumn{4}{|c|}{ Family Size } \\
\hline & 1 Child & 2 Children & 3 Children & All \\
\hline Child Education & $\begin{array}{l}13.27 \\
(0.13)\end{array}$ & $\begin{array}{l}13.41 \\
(0.06)\end{array}$ & $\begin{array}{l}13.15 \\
(0.05)\end{array}$ & $\begin{array}{l}13.28 \\
(0.04)\end{array}$ \\
\hline Education Help per Child & $\begin{array}{c}\$ 13,251 \\
(1,022)\end{array}$ & $\begin{array}{c}\$ 8,468 \\
(317)\end{array}$ & $\begin{array}{c}\$ 5,511 \\
(240)\end{array}$ & $\begin{array}{c}\$ 7,588 \\
(209)\end{array}$ \\
\hline Child Age & $\begin{array}{l}32.8 \\
(0.3)\end{array}$ & $\begin{array}{l}32.3 \\
(0.1)\end{array}$ & $\begin{array}{l}32.9 \\
(0.1)\end{array}$ & $\begin{array}{l}32.6 \\
(0.1)\end{array}$ \\
\hline Parent Household Income & $\begin{array}{c}\$ 34,791 \\
(1,854)\end{array}$ & $\begin{array}{c}\$ 43,415 \\
(1,095)\end{array}$ & $\begin{array}{c}\$ 40,111 \\
(880)\end{array}$ & $\begin{array}{c}\$ 41,056 \\
(659)\end{array}$ \\
\hline Parent Net Worth & $\begin{array}{l}\$ 202,946 \\
(24,968)\end{array}$ & $\begin{array}{c}\$ 241,832 \\
(11,948)\end{array}$ & $\begin{array}{c}\$ 245,436 \\
(12,347)\end{array}$ & $\begin{array}{c}\$ 239,648 \\
(8130)\end{array}$ \\
\hline Child Received Transfer Last Year & $\begin{array}{c}0.25 \\
(0.02)\end{array}$ & $\begin{array}{c}0.19 \\
(0.01)\end{array}$ & $\begin{array}{c}0.14 \\
(0.01)\end{array}$ & $\begin{array}{c}0.17 \\
(0.01)\end{array}$ \\
\hline Transfer Amount $\mid \mathrm{T}>0$ & $\begin{array}{c}\$ 3,172 \\
(642)\end{array}$ & $\begin{array}{c}\$ 2,239 \\
(171)\end{array}$ & $\begin{array}{c}\$ 2,708 \\
(297)\end{array}$ & $\begin{array}{c}\$ 2,543 \\
(165)\end{array}$ \\
\hline $\mathrm{N}$ & 318 & 1,436 & 1,475 & 3,229 \\
\hline
\end{tabular}




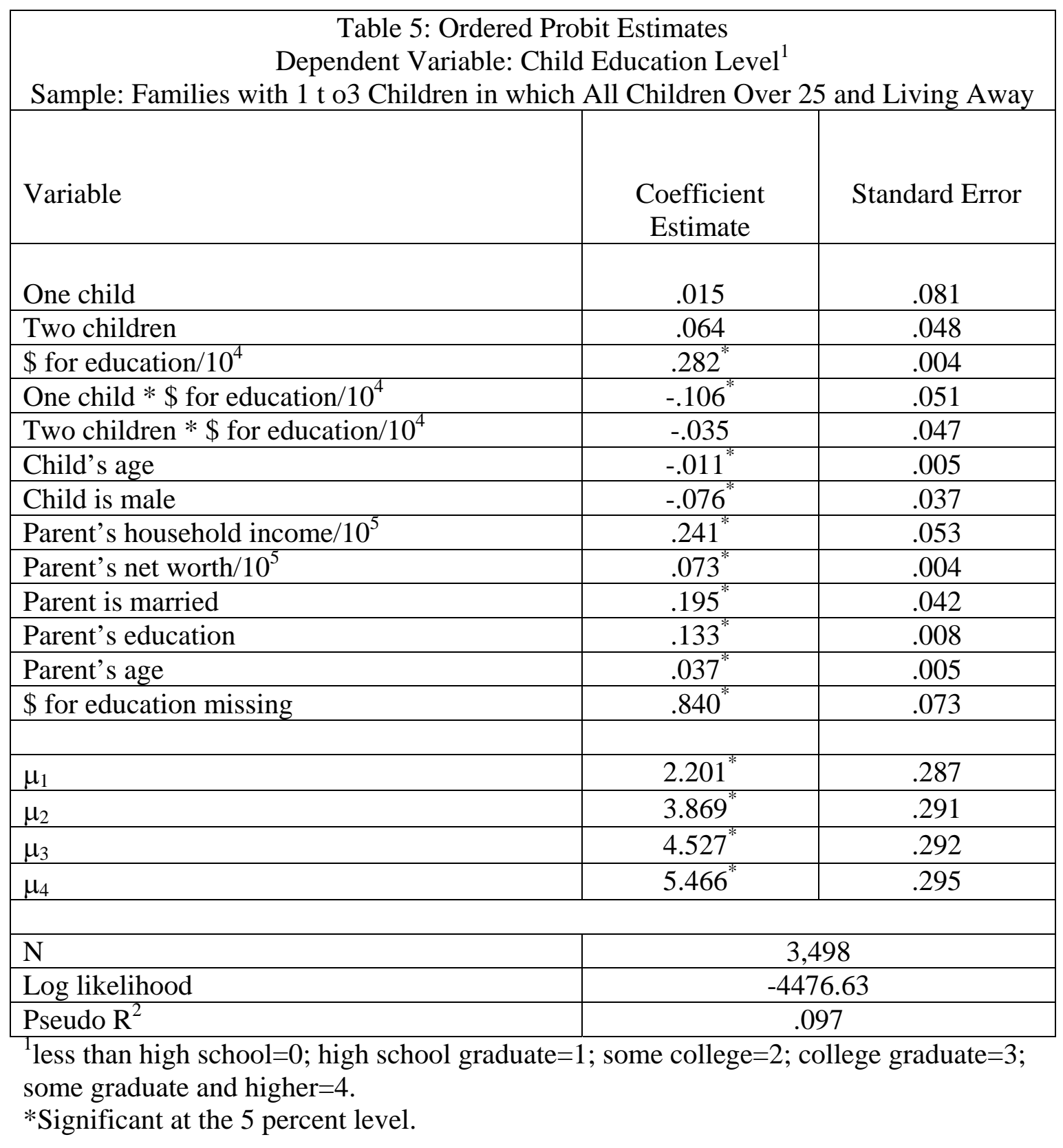


Figure 1

Child's Education Decision with and without Tied Transfers holding constant total cash value of first period transfer (parent saving $=\mathbf{- . 5 5}$ )

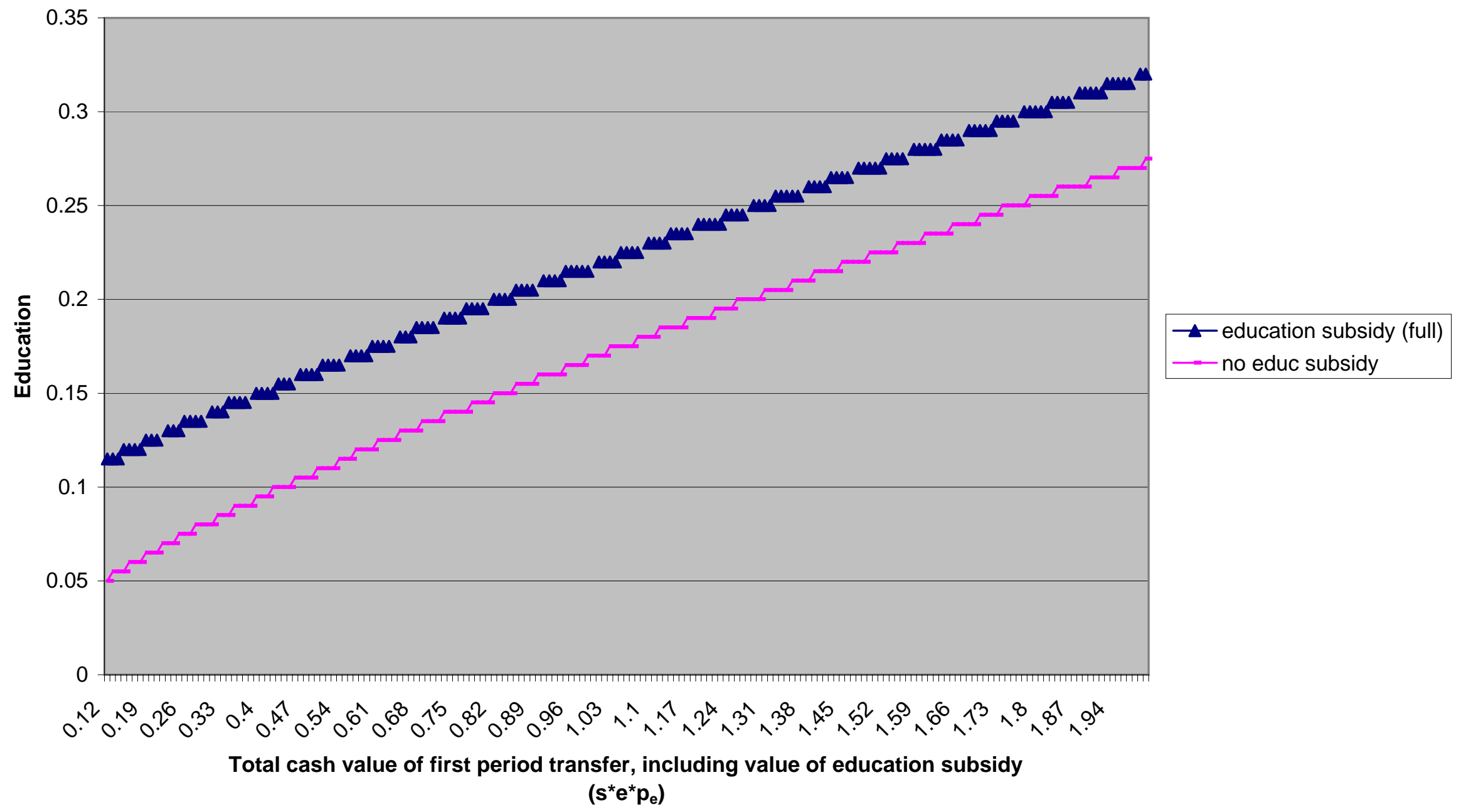


Figure 2: Education Choice by Degree of Altruism

(full education subsidy, no first period cash transfer, parent saving=-.04)

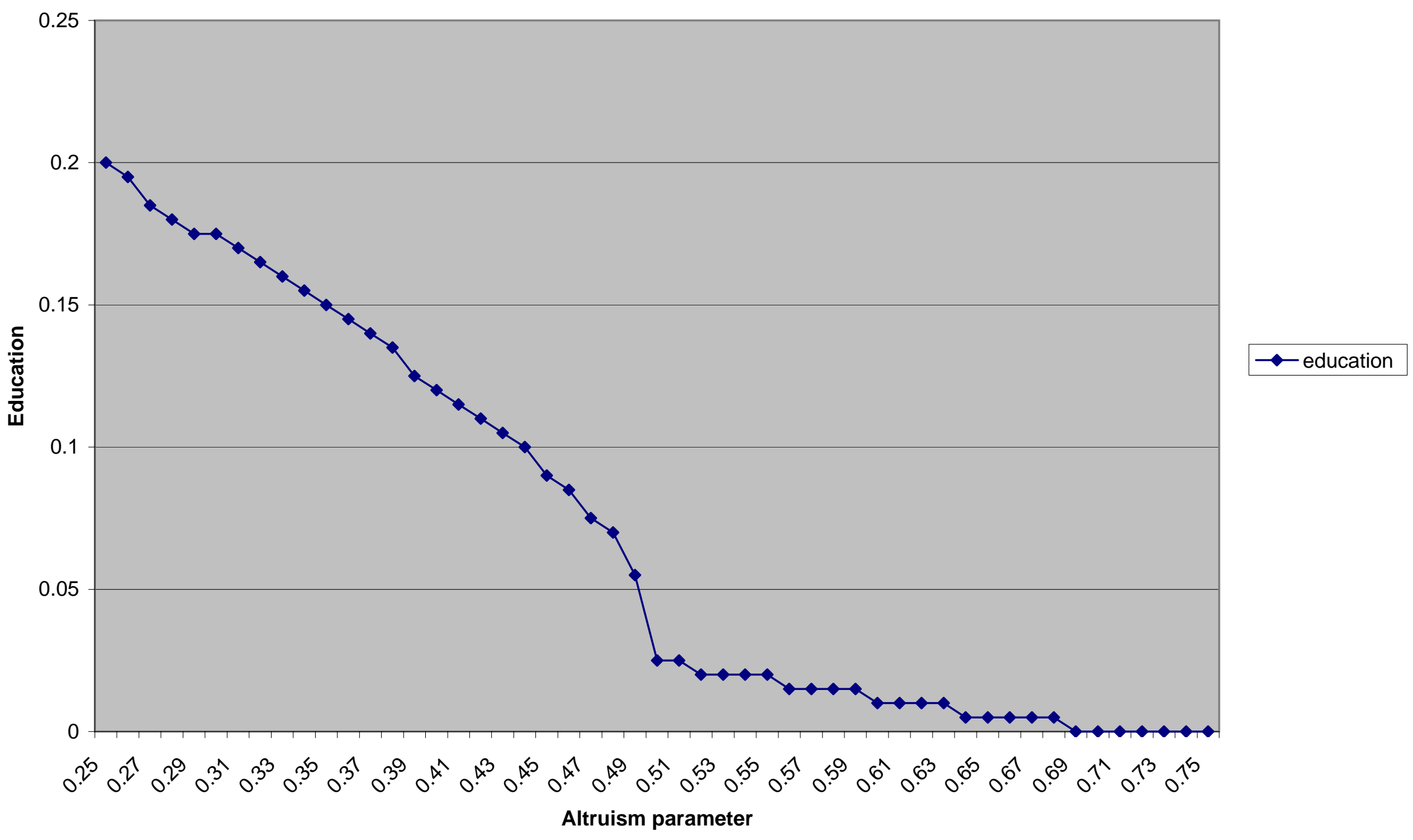


Figure 3

Education Decision by Family Size and First Period Cash Transfer

(given full education subsidy)

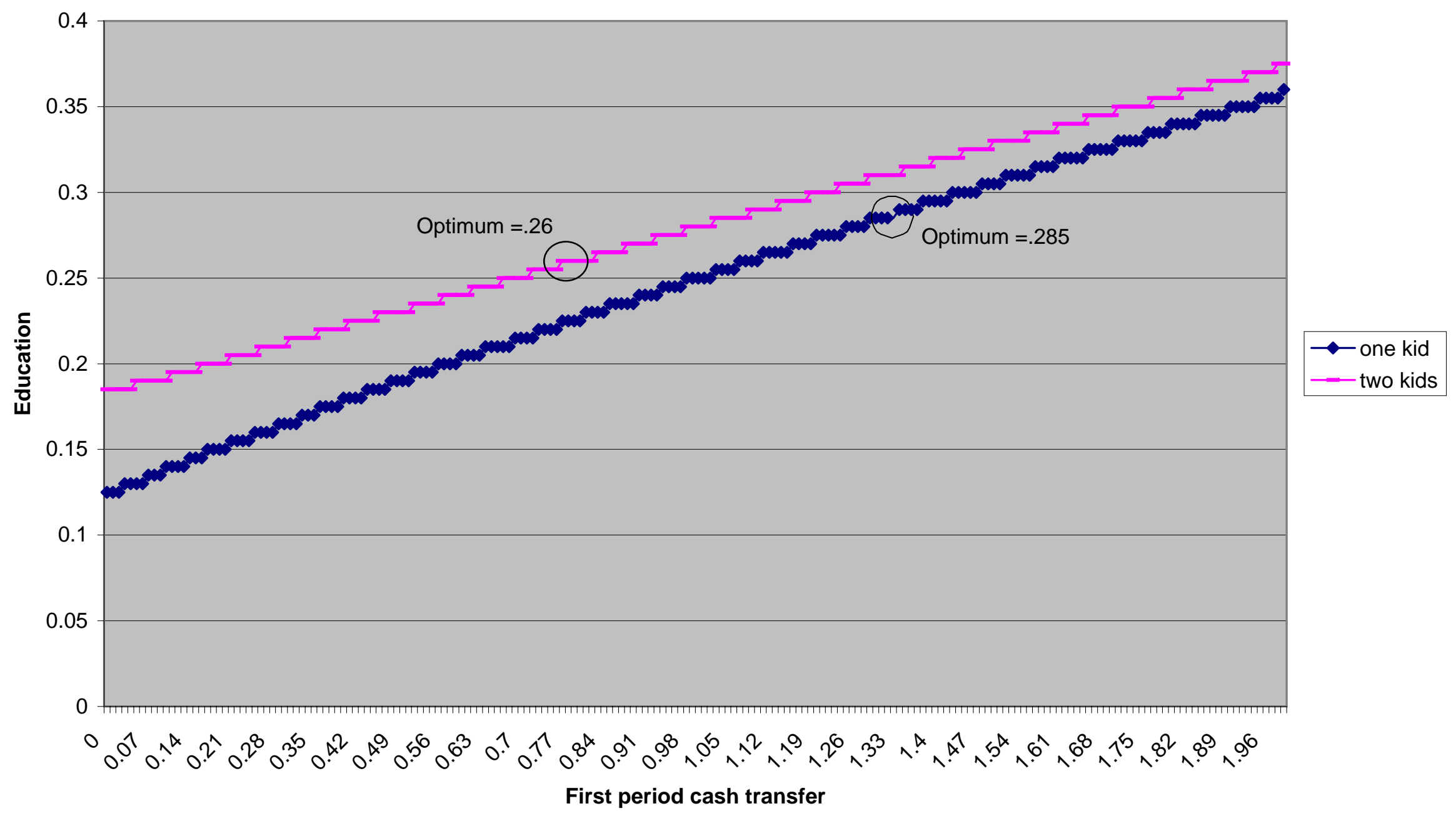




\section{References}

[1] Altonji, J., Hayashi, F., and Kotlikoff, L. "Is the Extended Family Altruistically Linked? Direct Tests Using Micro Data," The American Economic Review, 1992, vol. 82. no. 5. pp. 1177-1198.

[2] Becker, G. and Tomes, N. "Human Capital and the Rise and Fall of Families," Journal of Labor Economics, 1986, vol. 4, no. 3, pp. S1-S39.

[3] Bernheim, B.D. and Stark, O. "Altruism Within the Family Reconsidered: Do Nice Guys Finish Last?" The American Economic Review, 1988, vol. 78, no. 5, pp. 10341045.

[4] Brown, M., Mazzocco, M., Scholz, J.K. and Seshadri, A. "Tied Transfers," mimeo, 2004, University of Wisconsin-Madison.

[5] Bruce, N. and Waldman, M. "The Rotten Kid Theorem Meets the Samaritan's Dilemma," The Quarterly Journal of Economics, 1990, vol. 105, pp. 155-165.

[6] Bruce, N. and Waldman, M. "Transfers in Kind: Why They Can be Efficient and Nonpaternalistic," The American Economic Review, 1991, vol. 81, no. 5, pp. 1345-1351.

[7] Buchanan, J. "The Samaritan's Dilemma," in Altruism, Mortality and Economic Theory, ed. Edmund Phelps, New York, Russell Sage Foundation, 1975.

[8] Card, D. "The Causal Effect of Education on Earnings" in Handbook of Labor Economics, Elsevier Science, 2000.

[9] Coate, S. "Altruism, the Samaritan's Dilemma, and Government Transfer Policy," The American Economic Review, 1995, vol. 85, no. 1, pp. 46-57. 
[10] Cox, D. "Motives for Private Income Transfers," Journal of Political Economy, 1987, vol. 95, no. 3, pp. 508-546.

[11] Cox, D. "Intergenerational Transfers and Liquidity Constraints," The Quarterly Journal of Economics, 1990, vol. 105, pp. 187-217.

[12] Cox, D. and Raines, F. "Interfamily Transfers and Income Redistribution," in Horizontal Equity, Uncertainty and Economic Well-Being, ed. by M. David and T. Smeeding, Chicago, NBER and University of Chicago Press, 1985.

[13] Cox, D. and Rank, M. "Inter Vivos Trnasfers and Intergenerational Exchange," The Review of Economics and Statistics, 1992, vol. 74, no. 2, pp. 305-314.

[14] Gale, W. and Scholz J. K. "Intergenerational Transfers and the Accumulation of Wealth," The Journal of Economic Perspectives, 1994, vol. 8, no. 4, pp.145-160.

[15] Hayashi, F., Altonji, J., and Kotlikoff, L. "Risk Sharing Between and Within Families," Econometrica, 1996, vol. 64, no. 2, pp. 261-294.

[16] Juster, T. and Suzman, R. "The Health and Retirement Study: An Overview," Health and Retirement Study Working Paper Series, Core Paper No. 94-1001, Ann Arbor.

[17] Kotlkikoff, L. and Spivak, A. "The Family as an Incomplete Annuities Market," Journal of Political Economy, 1981, vol. 89, no. 2, pp. 372-391.

[18] Laitner, J. and Juster, F.T. "New Evidence on Altruism: A Study of TIAA-CREF Employees," The American Economic Review, 1996, vol. 86, no. 4, pp. 893-908.

[19] Lindbeck, A. and Weibull, J. "Altruism and Time Consistency: The Economics of Fait Accompli," Journal of Political Economy, 1988, vol. 96, no. 6, pp. 1165-1182. 
[20] McGarry, K. and Schoeni, R. "Transfer Behavior in the Health and Retirement Study: Measurement and Redistribution of Resources Within the Family," Journal of Human Resources, 1995, vol. 30, pp. S184-S226.

[21] Padula, M. and Pistaferri, L. "Education, Employment and Wage Risk," CSEF working paper, 2001.

[22] Perozek, M. "Essays on Intergenerational Transfers and Wealth Accumulation Over the Life Cycle," dissertation, University of Wisconsin-Madison, 1997.

[23] Pollak, R. "Tied Transfers and Paternalistic Preferences," The American Economic Review, 1988, vol. 78, no. 2, pp. 240-244.

[24] Rosenzweig, R. and Wolpin, K. "Intergenerational Support and the Life Cycle Incomes of Young Men and their Parents: Human Capital Investments, Coresidence, and Intergenerational Financial Transfers," Journal of Labor Economics, 1993, vol. 11, no. 1, pp. $84-112$.

[25] Saks, R. and Shore, S. "Risk and Career Choice," mimeo, 2004, Harvard University.

[26] Wilhelm, M. "Bequest Behavior and the Effect of Heirs' Earnings: Testing the Altruistic Model of Bequests," The American Economic Review, 1996, vol. 86, no. 4, pp. 874-892. 